\title{
Dual-Functional Peptide Driven Liposome Codelivery System for Efficient Treatment of Doxorubicin-Resistant Breast Cancer
}

\author{
Kamel S Ahmed (iD) ${ }^{1,2, *}$ \\ Shenhuan Liu' ${ }^{\prime} *$ \\ Jing Mao' \\ Jie Zhang ${ }^{3}$ \\ Lipeng Qiu (D)
}

\begin{abstract}
'School of Pharmaceutical Sciences, Jiangnan University, Wuxi, 214I22, Jiangsu, People's Republic of China; ${ }^{2}$ Department of Pharmaceutics, Faculty of Pharmacy, Minia University, Minia, 19623, Egypt; ${ }^{3}$ The Jiaxing Key Laboratory of Oncological Photodynamic Therapy and the Targeted Drug Research, College of Medicine, Jiaxing University, Jiaxing, Zhejiang, 31400I, People's Republic of China
\end{abstract}

*These authors contributed equally to this work

\begin{abstract}
Background: The active-targeted drug delivery systems had attracted more and more attention to efficiently overcome multidrug resistance (MDR) in cancer treatments. The aim of the work was to develop a multifunctional nano-structured liposomal system for codelivery of doxorubicin hydrochloride (DOX) and celecoxib (CEL) to overcome doxorubicin resistance in breast cancer.
\end{abstract}

Methods: A functional hybrid peptide (MTS- $\mathrm{R}_{8} \mathrm{H}_{3}$ ) with unique cellular penetrability, endolysosomal escape and mitochondrial targeting ability was successfully synthesized using solid phase synthesis technology. The peptide modified targeted liposomes (DOX/CELMTS- $\mathrm{R}_{8} \mathrm{H}_{3}$ lipo) for co-delivery of DOX and CEL were formulated to overcome the chemoresistance in MCF/ADR cells.

Results: DOX/CEL-MTS- $\mathrm{R}_{8} \mathrm{H}_{3}$ lipo showed nanosized shape and displayed high stability for one month. The cytotoxicity effect of the co-delivery of DOX and CEL through peptide modified liposomes had remarkable treatment efficacy on killing MCF/ADR cells. Targeted liposome exhibited greater cellular entry ability about 5.72-fold stronger than DOX solution. Moreover, as compared with unmodified liposomes, the presence of MTS- $\mathrm{R}_{8} \mathrm{H}_{3}$ peptide entity on liposome surface enhanced the mitochondrial-targeting ability and achieved effective reactive oxygen species (ROS) production with significant inhibition of P-gp efflux activity.

Conclusion: The study suggested that the DOX/CEL-MTS- $\mathrm{R}_{8} \mathrm{H}_{3}$ lipo is a promising strategy for overcoming drug resistance in breast cancer treatments with high targeting inhibition efficiency.

Keywords: doxorubicin hydrochloride, celecoxib, co-delivery, targeting liposomes, multidrug resistance

\section{Introduction}

Cancer remains the major public cause of death around the world and considered the 2 nd leading cause of death among American people. The three most public cancers for women are breast, lung, and colorectum, which together represent onehalf of all cancer cases. Among them, breast cancer alone accounts for $30 \%$ of all new cancer diagnoses in women and around $15 \%$ of all deaths. ${ }^{1}$ The combination of two or more chemotherapeutic agents with different mechanisms have been proved to be more effective than a single chemotherapy. ${ }^{2}$ As it was well known, the application of drug delivery systems provided numerous benefits as compared with single agents. Among various drug delivery systems, liposomes have attracted
Correspondence: Jie Zhang; Lipeng Qiu Email zhangjiepharm@zjxu.edu.cn; flyqlp@I63.com 
growing scientific interest because of their abilities to enhance drug bioavailability. The liposomes are attained cancer-targeting and drug resistance reversion ability through the enhanced permeability and retention effect (EPR), surface modifications and endocytosis. Previously reported studies proved that administration of peptidetargeted liposome containing chemotherapeutic drugs showed better synergistic therapeutic effect in the management of metastasis and chemoresistance than individual use of conventional liposome loaded with chemotherapeutic drug. ${ }^{3,4}$

Doxorubicin hydrochloride (DOX) is the frequently administered chemotherapy for the treatment of several types of cancer. However, cardiotoxicity in clinical rehearsal is the main side effect for DOX application. Moreover, the emergence of multiple drug resistance (MDR) in cancer cells decreases DOX efficiency. Among different MDR mechanisms, the P-glycoprotein overexpression (P-gp), an ATP-dependent efflux pump with wide xenobiotic compounds specificity, to pump drugs out of cells is one of the most popular reasons for MDR.

Besides most of the preclinical and clinical studies presented that COX-2 inhibitors specifically celecoxib (CEL) improves the chemotherapeutic effect of anticancer drugs, ${ }^{5-7}$ accordingly, it was proved that celecoxib enhances the growth inhibitory and apoptosis effect of doxorubicin in different cancer cell line, ${ }^{8-10}$ Moreover, celecoxib plays an important role in down-regulation of P-glycoprotein overexpression (P-gp), ${ }^{11,12}$ mitochondrial dysfunction and potentiation of ROS production. ${ }^{13}$ Mitochondrion is a vital multifunction organelle necessary for cellular activity. So, alteration of mitochondrial functions (ie depolarization of membrane potential, inhibition ATP synthesis, production of reactive oxygen species and cytochrome c release) is considered as the significant underlying cause of a variety of human diseases including cancer. $^{14-17}$ One commonly used approach to achieve effective intracellular entree is to conjugate the therapeutic agent with a cell penetrating peptide (CPP) such as octaarginine (R8) which primarily enter cells through adsorption-mediated endocytosis routes. ${ }^{18-20}$

In our previous work, we found that co-administration of DOX/CEL with liposomes was better and significantly enhanced the inhibition rate against B16 cells and MGC80-3 cells more than single-drug-loaded liposomes. Furthermore, dermarollers treatment prior to gel application strongly improved the topical anti-tumor efficacy against melanoma xenograft mice model. ${ }^{21}$ Despite the established connections between conventional DOX/CEL liposomes treatment and melanoma cell death and apoptosis, it has yet to be determined whether the co-drug loaded liposomes can improve the therapeutic efficacy in drugresistance breast cancer treatment by further promoting the targeting ability of liposomes.

The aim of the present study was to develop a multifunctional nano-structured liposomal system with ideal biocompatibility and biodegradability for co-delivery of DOX and CEL to overcome several challenges, including side effects of DOX, lower solubility of CEL, lack of specificity, limited stability, and a high capacity for disparate cargos. Furthermore, our main purpose was to get and enhance the therapeutic benefits resulted from the synergistic effect of DOX and CEL against breast cancer. To realize this potential, as shown in Scheme 1, peptide (MTS- $\mathrm{R}_{8} \mathrm{H}_{3}$ ) targeted liposomes with improved cell internalization, lysosomal escape and active mitochondrial targeting ability for multiple drug delivery were designed and evaluated.

\section{Materials and Methods Materials}

All amino acids were purchased from A Peptide Co., Ltd (Shanghai, China). Hydrogenated soya bean phosphatidylcholine (HSPC), 1,2-distearoyl-sn-glycero-3-phosphoethanolamine-N- [carboxy (polyethylene glycol)-2000] (sodium salt) DSPE-PEG (2000) were kindly gifted from Lipoid GmbH. Celecoxib (CEL) was supplied by energy chemical company. Doxorubicin hydrochloride (DOX) was supplied by Beijing Huafeng United Technology Co. Ltd. (Beijing, China). N-hydroxysuccinimide (NHS), 1-ethyl-3-(3-dimethyl aminopropyl) carbodiimide (EDC), and Cholesterol $(\mathrm{CH})$ were purchased from Aladdin Regent Co. (Shanghai, China). RPMI 1640 medium, fetal bovine serum (FBS), penicillin-streptomycin solution, and 3-(4,5-dimethylthiazol-2-yl)-2,5-diphenyl tetrazolium bromide (MTT) were obtained from Life Technologies ${ }^{\mathrm{TM}}$. 5,5',6,6'-tetrachloro-1, $1^{\prime}, 3,3^{\prime}$ -

tetraethylbenzimidazolcarbocyanine iodide (JC-1) and 4', 6-diamidino-2-phenylindole (DAPI) were supplied by Shanghai Beyotime Biotechnology Co. Ltd. (Suzhou, China). MCF/ADR human breast cancer cells were bought from the Type Culture Collection of the Chinese Academy of Sciences (Shanghai, China). Chloroform and all other chemicals were of analytical grade. 


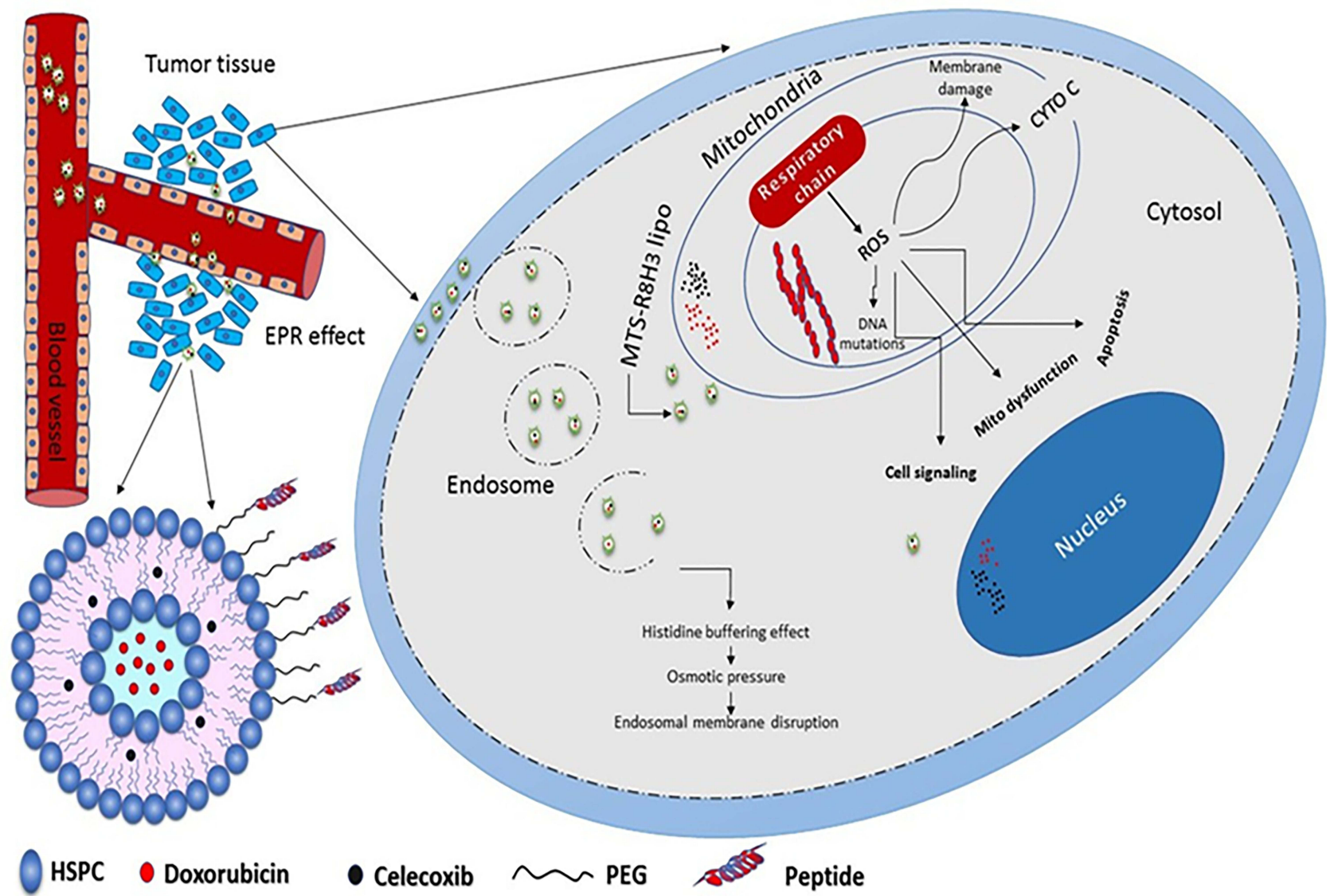

Scheme I A schematic illustration of the pathway of DOX/CEL-loaded targeting liposomes, targeted liposomes were taken up into tumor cells by endocytosis pathway and escaped from lysosomes into mitochondria and nucleus. Peptide: $M T S-\mathrm{R}_{8} \mathrm{H}_{3}$.

Abbreviation: Cyto $\mathrm{C}$, Cytochrome $\mathrm{C}$.

\section{Cell Cultures}

MCF/ADR human breast cancer cells were grown in RPMI 1640 medium containing $1 \mu \mathrm{g} / \mathrm{mL}$ doxorubicin $\mathrm{HCl}, 10 \% \mathrm{FBS}, 100 \mathrm{U} / \mathrm{mL}$ penicillin and $100 \mathrm{mg} / \mathrm{mL}$ streptomycin. The cells were cultured at $37{ }^{\circ} \mathrm{C}$ and $5 \%$ $\mathrm{CO}_{2}$ in a humidified incubator.

\section{Synthesis of the Multifunctional MTS- $\mathrm{R}_{8} \mathrm{H}_{3}$ Peptide}

A functional hybrid peptide conjugation approach that incorporates CPP, histidines, and MTS into one molecule with a sequence of MLRAALSTARRGPRLSRLLHHH RRRRRRRR was employed to improve the cellular penetrability, endo-lysosomal escape and mitochondrial targeting efficacy in human MCF/ADR cells. All amino acids conjugates were prepared using standard 9-fluorenylmethyloxycarbonyl (Fmoc) solid phase synthesis approaches. The amino acids, Fmoc-Arg (Pbf)-OH, FmocGly-OH, Fmoc-Met-OH, Fmoc-Leu-OH, Fmoc-Ala-OH, Fmoc-Ser (But)-OH, Fmoc-Pro-OH, Fmoc-Thr (But)-OH,
Fmoc-His (Trt)-OH, etc. added in a reaction tube containing Wang resin with a degree of substitution of $1.03 \mathrm{mmol} /$ g. Fmoc deprotections were carried out using a $20 \%$ piperidine DMF solution $(15 \mathrm{~mL} / \mathrm{g})$ for $5 \mathrm{~min}$. Acetylation was performed on $\alpha$-amino groups of $\mathrm{N}$-terminus amino acids using a $20 \%$ acetic anhydride in DMF (N, $\mathrm{N}$-dimethylformamide) solution with $100 \mu \mathrm{L}$ DIEA (diisopropylethylamine). After pumping out the piperidine solution, some resins were taken and washed three times with ethanol, followed by addition of detection reagents (Phenol reagent, pyridine reagent, ninhydrin reagent) to monitor the reaction. The resin was washed twice using DMF $(10 \mathrm{~mL} / \mathrm{g})$, methanol $(10 \mathrm{~mL} / \mathrm{g})$, dichloromethane $(10 \mathrm{~mL} / \mathrm{g})$, and drained for $10 \mathrm{~min}$. Completed peptides were separated from the resin using the cleavage cocktail (95\% trifluoroacetic acid; $1 \%$ water; $2 \%$ ethanedithiol and $2 \%$ triisopropylsilane) for $120 \mathrm{~min}$. Finally, the lysate was dried with nitrogen, washed six times with diethyl ether, and then evaporated at room temperature. The crude product was purified by high-performance liquid 
chromatography (HPLC, Shimadzu, Japan) and then lyophilized to obtain the MTS- $\mathrm{R}_{8} \mathrm{H}_{3}$ peptide. The peptide was confirmed using HPLC and mass spectrum (MS, Waters, USA).

\section{Synthesis of DSPE-PEG2000-MTS- $\mathrm{R}_{8} \mathrm{H}_{3}$ Conjugates}

DSPE-PEG2000-MTS- $\mathrm{R}_{8} \mathrm{H}_{3}$ conjugate was synthesized and purified according to an established procedure with some modifications. ${ }^{3}$ Firstly, DSPE-PEG2000 was allowed to react with NHS/EDC in DMF for 4h in an ice bath with gentle stirring to activate the carboxylic group of DSPEPEG2000. The peptide was added to the above solution in an appropriate molar ratio (DSPE-PEG2000: NHS: EDC: peptide is $2: 4: 4: 1$ ) and stirred for $24 \mathrm{~h}$ at room temperature under nitrogen protection. The resulting solution was dialyzed in deionized water with a cellulose ester membrane filter $(\mathrm{MWCO}=3500 \mathrm{Da})$ for $48 \mathrm{~h}$ to remove un-reacted species. Finally, the dialysate was concentrated and lyophilized to obtain DSPE-PEG2000- MTS- $\mathrm{R}_{8} \mathrm{H}_{3}$. The conjugate was collected and identified by Fourier transform infrared spectra (Bruker Instruments, Beijing, China), and ${ }^{1} \mathrm{H}$ NMR spectrometry (AVANCE III, $400 \mathrm{MHz}$, Bruker, Germany).

\section{Preparation and Characterization of the Liposomes}

The liposomes were formulated according to the widely used thin film hydration method and post-insertion technique. ${ }^{23,24}$ The lipid phase was composed of hydrogenated soya bean phosphatidylcholine $60 \mathrm{mmol}$ and cholesterol with $\mathrm{HSPC} / \mathrm{CH}$ molar ratio 1:1. These components were dissolved in chloroform in a round-bottom flask together with an appropriate amount of CEL. Chloroform was slowly evaporated using a rotary evaporator under vacuum forming a thin lipid film on the flask wall that was further dried in a vacuum chamber overnight. The lipid film was then hydrated by ammonium sulfate solution to form multilamellar vesicle suspension that was further subjected to ultrasonication using a probe sonicator for 10 min at 40\% (JY92-IIN, Ningbo Scientz Biotechnology Co., Ltd., China) to prepare CEL loading liposomes (CEL lipo). Based on the above procedure, the $\mathrm{pH}$ gradient system of the liposomes was constructed by removing unentrapped ammonium sulfate through dialysis against a buffer solution. DOX was loaded by mixing the drug solution at $60{ }^{\circ} \mathrm{C}$ for $15 \mathrm{~min}$ with the liposome's suspension. Free DOX was separated by the dialysis method to prepare DOX/CEL loading liposomes (DOX/ CEL lipo). DOX-loaded liposomes (DOX lipo) were prepared using the above method, but without adding CEL to the lipid components.

For preparing of the peptide-modified DOX/CELMTS- $\mathrm{R}_{8} \mathrm{H}_{3}$ liposomes (targeting lipo), blank liposomes composed of HSPC and $\mathrm{CH}$ were first prepared, and the procedure was the same as described above. DSPEPEG2000-MTS- $\mathrm{R}_{8} \mathrm{H}_{3}$ at $4 \mathrm{~mol} \%$ of HSPC was then added into the preformed liposome suspension under stirring for $1 \mathrm{~h}$ at $60{ }^{\circ} \mathrm{C}$ in the dark. ${ }^{25}$ The mixture was then dialyzed against phosphate buffer using semi-permeable dialysis membrane (MWCO $14000 \mathrm{Da}$ ) for $4 \mathrm{~h}$ to remove unconjugated ligands.

The particle size and zeta potential of the liposomes were measured by dynamic light scattering (DLS) using a Zetasizer Nano ZS apparatus (Malvern Instruments, UK). The morphology of the liposomes was determined by transmission electron microscopy (TEM) on a JEM2100 (JEOL, Japan).

The encapsulation efficiency was tested by ultraviolet spectrophotometry. The unencapsulated DOX and CEL were removed by means of ultrafiltration using centrifugal filter tubes with an Mwt cut-off of (3000 MWCO) (Millipore, Suzhou, China). Liposome suspension was placed into the filter tubes and centrifuged at $5000 \mathrm{rpm}$ and $4{ }^{\circ} \mathrm{C}$ for $20 \mathrm{~min}$. The drug solution collected at the bottom of the filter tube was analyzed by ultraviolet spectrophotometric assay (UV-2550, Shimadzu, Japan) to determine DOX and CEL content at $486 \mathrm{~nm}$ and $256 \mathrm{~nm}$ respectively.

\section{In vitro Drug Release Study}

In vitro DOX and CEL released from liposomes was determined using a semi-permeable dialysis membrane (MWCO $14000 \mathrm{Da}$ ). The dialysis membrane was sited between the donor and receptor compartments of modified Franz diffusion cells. After separating unencapsulated drugs, $1 \mathrm{~mL}$ of liposome formulations was applied on the dialysis membrane surface. The receptor compartment was filled with $20 \mathrm{~mL}$ fresh PBS buffer medium ( $\mathrm{pH}$ 7.4) containing ammonium sulfate ${ }^{26}$ and $1 \%$ sodium dodecyl sulfate $^{27}$ at $37{ }^{\circ} \mathrm{C}$ and $90 \mathrm{rpm}$. At predetermined time intervals, $2 \mathrm{~mL}$ of the sample was withdrawn from the receptor medium and substituted with the same amount of buffer phosphate to keep perfect sink conditions. The drug concentrations were measured by ultraviolet 
spectrophotometric assay at $486 \mathrm{~nm}$ and $256 \mathrm{~nm}$, respectively. The results were the average of the three runs, and the cumulative percent released of each drug was plotted at a certain time.

\section{Assessment of Liposome Stability}

Different drug-loaded liposomes made from hydrogenated soya bean phosphatidylcholine formulated under the same conditions were stored at $4{ }^{\circ} \mathrm{C}$ for 1 month. Liposomal size, PDI and entrapment efficiency were the parameters chosen to indicate the physical stability of liposomes.

\section{Cytotoxicity Studies}

The cytotoxicity of different liposomal formulations against MCF/ADR cells was evaluated by MTT assay. MCF/ADR cells were seeded in 96-well plate at a density of $8 \times 10^{3}$ cells per well, and the cells were adhered by overnight culture. The cell culture medium was discarded and replaced with fresh medium containing different drug formulations. For the cytotoxic effect of empty liposome and empty targeted liposome, 100 $\mu \mathrm{L}$ of $0.3 \mathrm{mmol} / \mathrm{mL}$ (correspond to the highest lipid concentration used in drug-loaded liposomes for viability test) was added to one set of 96-well plate to incubate with MCF/ADR cells. After 48 hours of incubation, $100 \mu \mathrm{L}$ of MTT solution was added. MTT was removed after $4 \mathrm{~h}$ incubation. Finally, $100 \mu \mathrm{L}$ of DMSO was added to dissolve the formazan blueviolet crystals, formed by the living cells, before measurement at $580 \mathrm{~nm}$ with a microplate reader (Multiskan MK3, Thermo, USA).

\section{Cellular Uptake Analysis}

Cellular uptake of free DOX, DOX lipo, DOX/CEL lipo, and targeting lipo by $\mathrm{MCF} / \mathrm{ADR}$ cells was studied by qualitative fluorescence imaging and quantitative flow cytometry. The cells were seeded into a laser confocal dish at a density of $8 \times 10^{4}$ cells per well and cultured overnight for adherence. After that, the culture medium was replaced with different drug formulations with a DOX and CEL concentrations of 5 and $20 \mu \mathrm{g} \cdot \mathrm{mL}^{-1}$ respectively and then the cells were incubated for $1 \mathrm{~h}, 2 \mathrm{~h}$, and 4 h. After being washed with phosphate-buffered saline (PBS), $200 \mu \mathrm{L}$ of $4 \%$ paraformaldehyde was added into each well to fix cells for $20 \mathrm{~min}$. Then the nuclei were stained with DAPI $\left(20 \mu \mathrm{g} \cdot \mathrm{mL}^{-1}\right)$ for $15 \mathrm{~min}$, followed by washing the cells three times using PBS. Finally, $500 \mu \mathrm{L}$ of PBS was added to each well. The cell uptake was observed using confocal laser scanning microscopy (CLSM, Nikon A1R, Japan).

For flow cytometry analysis, MCF/ADR cells were seeded in 6 -well plates at $2 \times 10^{5}$ cells per well, and the cells were adhered by overnight incubation at $37^{\circ} \mathrm{C}$ and $5 \% \mathrm{CO}_{2}$. Then the medium was replaced with different formulations with DOX and CEL concentrations of 5 and $20 \mu \mathrm{g} \cdot \mathrm{mL}^{-1}$ respectively. The plates were incubated for 1 h, $2 \mathrm{~h}$, and $4 \mathrm{~h}$. Followed by washing the cells three times with PBS, $200 \mu \mathrm{L}$ of trypsin enzyme was added to each well. After being digested, the cells were collected and centrifuged. The resulting cells were suspended in 500 $\mu \mathrm{L}$ of PBS and the fluorescence intensity was evaluated by flow cytometry (Becton Dickinson FACSCalibur, USA).

\section{Subcellular Localization of the Liposomes}

The distribution of different liposomal formulations in $\mathrm{MCF} / \mathrm{ADR}$ tumor cells was observed by confocal laser scanning microscopy (CLSM, Leica, TCS SP8, Germany). MCF/ADR cells were seeded onto a glass bottom cell culture dish $(\varphi 15 \mathrm{~mm})$ at $20 \times 10^{5}$ cells per well and cultured overnight for adherence. Then, the culture medium was removed, and preparations were added with DOX and CEL concentrations of 5 and 20 $\mu \mathrm{g} \cdot \mathrm{mL}^{-1}$ respectively. The culture plates were incubated for $1 \mathrm{~h}, 2 \mathrm{~h}$, and $4 \mathrm{~h}$, and the cells were washed with PBS and stained by lysotracker green $(50 \mathrm{~nm})$ for $30 \mathrm{~min}$ and DAPI for $20 \mathrm{~min}$ to visualize the endo-lysosomes and the nucleus respectively, followed by addition of $200 \mu \mathrm{L}$ of $4 \%$ paraformaldehyde into each well to fix cells. Finally, the plates washed three times using PBS and then observed by confocal laser scanning microscopy (CLSM, Nikon A1R, Japan).

For further tracking the internalization and the mitochondrial targeting ability of different liposomal formulations in MCF/ADR tumor cells, the cells were treated with liposomal preparations at a concentration of $5 \mu \mathrm{g} \cdot \mathrm{mL}^{-1}$ and $20 \mu \mathrm{g} \cdot \mathrm{mL}^{-1}$ for DOX and CEL, respectively. After incubation for $1 \mathrm{~h}, 2 \mathrm{~h}$, and $4 \mathrm{~h}$, the cells were rinsed with cold PBS twice, and mitochondrion staining was performed with Mitotracker Green for $30 \mathrm{~min}$ at $37{ }^{\circ} \mathrm{C}$. Then, the cells were counterstained with DAPI (blue fluorescence) for $20 \mathrm{~min}$ to visualize the cellular nuclei and observed by CLSM. 


\section{Mitochondrial Membrane Potential Assay (MMP)}

Mitochondrial membrane-permeable lipophilic cationic fluorochromes are applied as probes of $\Delta \psi$, they permeate cells and their fluorescence reflects the change in MMP. ${ }^{28}$ Most of the recently published literature using 5,5',6,6'tetrachloro-1,1',3,3'-tetraethyl benzimidazole carbocyanine iodide (JC-1) to evaluate $\Delta \psi,{ }^{29,30} \mathrm{JC}-1$ is a lipophilic fluorochrome that is used to assess the status of the $\Delta \psi$, it can exist in two different states, monomers green $(\sim 525$ $\mathrm{nm})$ or aggregates red $(\sim 590 \mathrm{~nm})$, each with a different emission spectrum. MCF-7/ADR cells were cultured in 6-well plates $\left(1 \times 10^{6}\right.$ cell/well $)$ and incubated for $24 \mathrm{~h}$, and then the cells were incubated with different drug formulations in $5 \% \mathrm{CO} 2$ incubator at $37^{\circ} \mathrm{C}$ for $4 \mathrm{~h}$. after incubation time the cells were washed three times and stained with JC-1 working solution for another $30 \mathrm{~min}$. Finally, the cells were collected, centrifuged and washed thrice with PBS. MMP was measured as the ratio of red/ green fluorescence intensity. The fluorescence of green $($ emission $=538 \mathrm{~nm})$ and red (emission $=590 \mathrm{~nm}$ ) was analyzed by flow cytometry (Becton Dickinson FACSCalibur, USA).

\section{Production of Reactive Oxygen Species (ROS)}

Dichlorofluorescein diacetate (DCFH-DA) assay was performed to measure ROS generation. ${ }^{13,31}$ DCFH-DA can readily enter cells and be cleaved by esterase to yield $\mathrm{DCFH}$, nonfluorescent polar product. ROS in cells promote the oxidation of DCFH to yield the fluorescent product dichlorofluorescein. MCF/ADR cells were incubated in a six-well plate and exposed to different formulations for $1 \mathrm{~h}, 2 \mathrm{~h}$, and $4 \mathrm{~h}$. After the pretreatment period, cells were incubated with DCFH-DA at $37{ }^{\circ} \mathrm{C}$ in the culture medium for $30 \mathrm{~min}$. After incubation, the cells were washed by PBS three times. Each well was digested by $200 \mu \mathrm{L}$ of trypsin enzyme, re-suspended in $500 \mu \mathrm{L}$ PBS, and immediately submitted to flow analysis using a flow cytometer (Becton Dickinson FACSCalibur, USA).

\section{Analysis of P-gP Efflux Activity}

The intracellular rhodamine 123 accumulation was taken as an index to evaluate the efflux pump activity of P-gp. ${ }^{32}$ $\mathrm{MCF} / \mathrm{ADR}$ cells were cultured in six-well plates at initial densities of $5 \times 10^{6} /$ well and incubated for $24 \mathrm{~h}$. Then, cells were treated with different DOX formulations for 12 and
$24 \mathrm{~h}$, after incubation time, the medium was discarded, and the cells rinsed three times with PBS. Cells were incubated with $\mathrm{Rh} 123(5 \mu \mathrm{g} / \mathrm{mL})$ for $30 \mathrm{~min}$ in darkness at $37{ }^{\circ} \mathrm{C}$. Finally, cells were washed twice with PBS. The cells were digested, centrifuged, and suspended with $1 \mathrm{~mL}$ PBS. The fluorescence as an indicator for intracellular Rh123 accumulation was analyzed by flow cytometry (Becton Dickinson FACSCalibur, USA).

\section{Statistical Analysis}

The measurements were repeated at least three times. All reported values present mean values \pm standard deviation. The data were subjected to analysis of variance using oneway ANOVA (SPSS 17.0, Chicago, IL, USA), a value of $\mathrm{P}<0.05$ was considered as a minimal level of significance.

\section{Results and Discussion}

\section{Synthesis and Characterization of MTS- $\mathrm{R}_{8} \mathrm{H}_{3}$ and DSPE-PEG-MTS- $\mathrm{R}_{8} \mathrm{H}_{3}$}

Solid phase synthesis approach was used to prepare MTS- $\mathrm{R}_{8} \mathrm{H}_{3}$ peptide. The purity of the MTS- $\mathrm{R}_{8} \mathrm{H}_{3}$ conjugate was above $95 \%$ according to analytical HPLC analysis (Supplementary Materials Figure S1). The multiply charged ions of ESI-MS showed that the mass of the conjugate was $3799.57 \mathrm{Da}$ (Supplementary Materials Figure S2), which was agreed with the calculated exact masses of the peptide.

DSPE-PEG-MTS- $\mathrm{R}_{8} \mathrm{H}_{3}$ was produced via a nucleophilic substitution reaction, in which the terminal amino group on MTS- $\mathrm{R}_{8} \mathrm{H}_{3}$ peptides reacted with the carboxylic group of DSPE-PEG in anhydrous DMF (Figure 1). The resulting product was characterized by ${ }^{1} \mathrm{H}$ NMR spectra and IR. As shown in Figure 2A, the peaks at $0.843 \mathrm{ppm}$ and $1.226 \mathrm{ppm}$ were belonged to methyl and methylene protons in DSPE, while the peaks at $3.509 \mathrm{ppm}$ and $6.5-8.5 \mathrm{ppm}$ were attributed to PEG and MTS- $\mathrm{R}_{8} \mathrm{H}_{3}$, respectively. In the Fourier transform infrared spectrum (Figure 2B), the peak at $1106 \mathrm{~cm}^{-1}$ was the stretching vibration of $\mathrm{C}-\mathrm{O}-\mathrm{C}$ in the $\mathrm{PEG}$ segment and the peak at $1645 \mathrm{~cm}^{-1}$ was the stretching vibration of $\mathrm{C}$ $(=\mathrm{O})-\mathrm{N}$ in $\mathrm{MTS}-\mathrm{R}_{8} \mathrm{H}_{3}$. All the data confirmed that the conjugation reaction successfully proceeded.

\section{Characterization of DOX/CEL Liposomes}

Drug-loaded targeting liposomes were formulated using thin film hydration method with $\mathrm{pH}$ gradient and post insertion techniques. Liposomes were prepared in the 

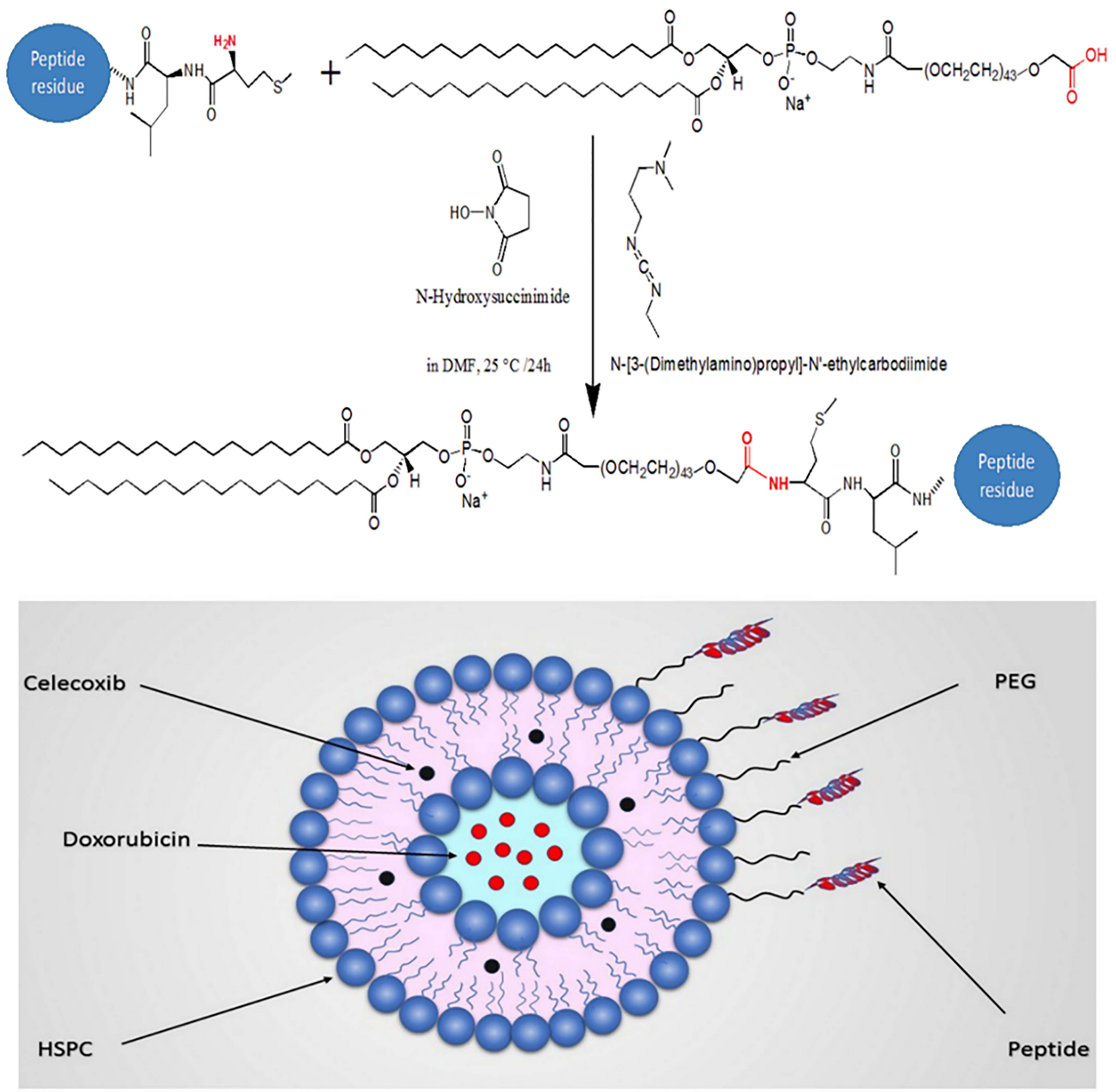

Figure I Synthesis scheme of peptide $\left(\mathrm{MTS}-\mathrm{R}_{8} \mathrm{H}_{3}\right)$ and the illustration of liposome composition.

presence of DSPE-PEG2000 to promote conjugation of MTS- $\mathrm{R}_{8} \mathrm{H}_{3}$ peptides to liposomal surfaces as an active targeting ligand. The average diameter for all liposomes was approximately similar, in a range of $100-150 \mathrm{~nm}$, and had a highly homogeneous distribution with a PDI less than 0.2 (Table 1). Nanoparticles with such homogeneity have been reported to endow the liposomal delivery system for higher therapeutic effect through EPR effect in vivo. ${ }^{33,34}$ Conjugation of MTS- $\mathrm{R}_{8} \mathrm{H}_{3}$ peptides increased the vesicle size to approximately $176.16 \pm 1.68 \mathrm{~nm}$, indicating the presence of targeting ligands on the liposome's surfaces. Particle sizes of the targeting liposome were further investigated by TEM imaging. Liposomes displayed nanosized, spherical morphologies and uniform distribution on TEM grids (Figure 3A). Table 1 lists the measured particle size, PDI, zeta potential and entrapment efficiency of liposomes. In all preparations, the encapsulation efficiencies of doxorubicin and celecoxib were approximate $>96 \%$ consistent with the previously published results about the liposomal formulation of doxorubicin hydrochloride with Palm Oil (EE $\%$ about $99 \%)^{35}$ 
A

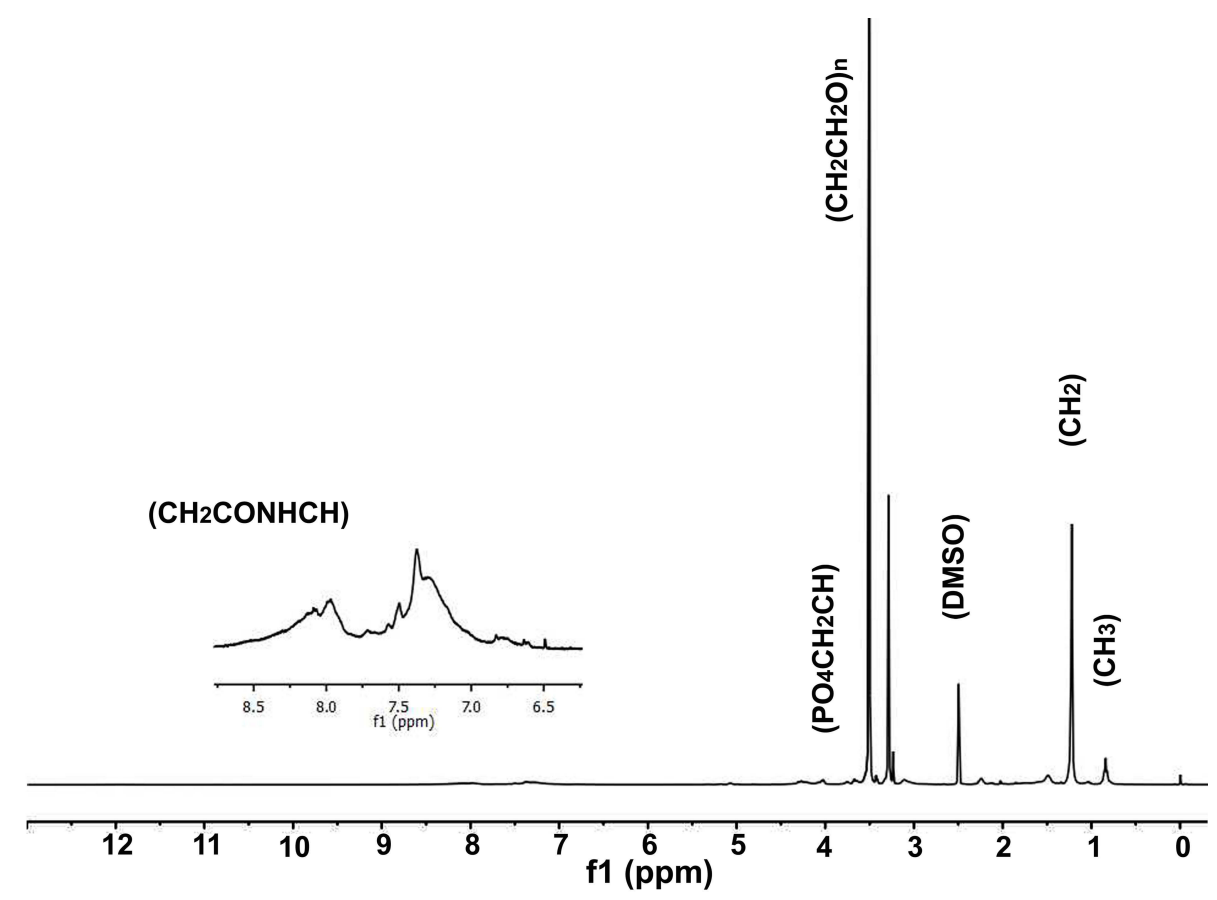

B

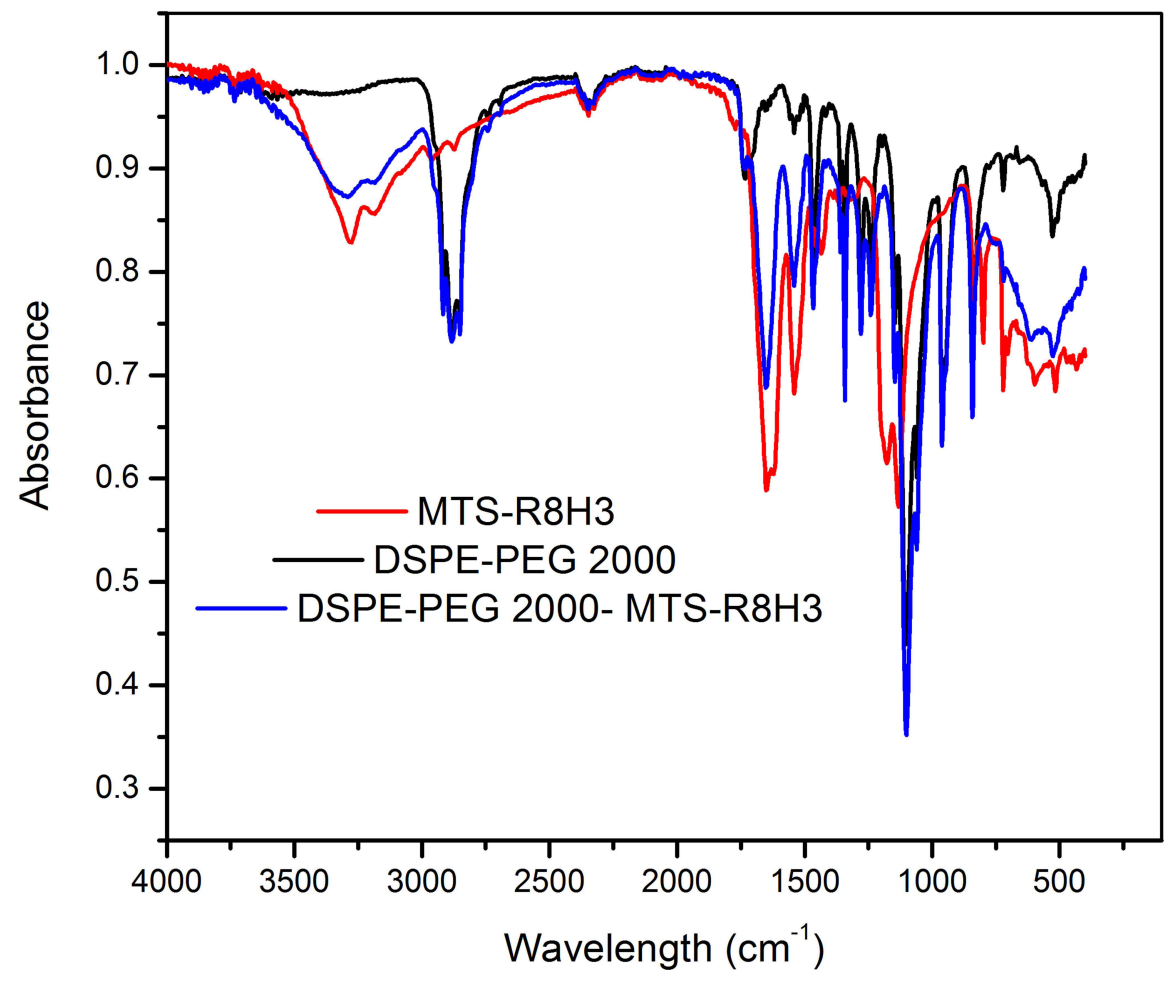

Figure 2 'H-NMR spectroscopy (A) and Fourier transform infrared spectra (B) of DSPE-PEG 2000, MTS- ${ }_{8} \mathrm{H}_{3}$, and DSPE-PEG 2000- MTS-R $\mathrm{H}_{3}$.

\section{Drug-Release Studies}

In vitro drug release study was performed to evaluate the liposomal drug release property in PBS ( $\mathrm{pH}$ 7.4) containing $1 \% \mathrm{w} / \mathrm{v}$ sodium lauryl sulfate. As shown in Figure 3C, not a large burst release was observed initially, and only about $40 \%$ of total DOX and CEL were released in the first $12 \mathrm{~h}$, followed by a lower drug release phase within the later 72 $\mathrm{h}$. Presence of ammonium sulfate in the receptor medium enhanced the release of DOX from the internal part of the liposomal vesicle. ${ }^{36}$ Drug release from the targeted liposomal formulation displayed similar and sustained release manners without significant initial burst release. 
Table I The Size, PDI, Zeta-Potential and Encapsulation Efficiency of Different Liposomes. Values are Means \pm Standard Deviation for Three Independent Experiments

\begin{tabular}{|l|c|c|c|c|c|}
\hline \multirow{2}{*}{ Drug Formulations } & \multicolumn{2}{|c|}{ Encapsulation Efficiency \% } & \multirow{2}{*}{ Particle Size (nm) } & \multirow{2}{*}{ PDI } & Zeta Potential \\
\cline { 2 - 3 } & Doxorubicin & Celecoxib & & & \\
\hline DOX lipo & $99.2 \% \pm 0.003$ & & $112.43 \pm 3.48$ & $0.127 \pm 0.016$ & $-2.24 \pm 0.43$ \\
DOX/CEL lipo & $98.37 \% \pm 0.037$ & $99.69 \% \pm 0.0014$ & $141.6 \pm 4.015$ & $0.179 \pm 0.014$ & $-3.15 \pm 0.09$ \\
Targeting lipo & $96.37 \% \pm 0.316$ & $97.69 \% \pm 0.158$ & $176.16 \pm 1.68$ & $0.193 \pm 0.001$ & $-4.01 \pm 0.81$ \\
\hline
\end{tabular}

\section{Stability Study}

Physical stability is a critical issue that must be considered during preparation design and development. The liposomal physical instability might be apparent after an increase in vesicle size as a result of the fusion or aggregation of unstable particles during preparation processing or upon storage for a long time. Accordingly, this instability leads to short half-life due to the quick uptake by the reticuloendothelial system, resulting in rapid body clearance and consequently decreased therapeutic efficacy of the loaded drug. So, small and uniform liposomal size preparation is the most vital factor for developing useful and effective pharmaceutical products. ${ }^{37}$

The stability of liposomes was evaluated at $4{ }^{\circ} \mathrm{C}$ and protected from direct light for one month. The data showed that liposomes did not display significant changes in particle size and PDI with a little change in the entrapment efficiency of both drugs (Figure 3B and Table 2). This long-term stability resulted from the incorporation of saturated phospholipids and cholesterol that lead to decrease in the lipid bilayer defect, improve the lateral packing of the acyl chains and consequently, minimizing leakage of liposomal contents. ${ }^{38}$

\section{Cytotoxicity Studies of Liposomes}

MTT assay was applied to evaluate the cytostatic efficacy of DOX and CEL on MCF/ADR cells. Tumor cells were exhibited to the liposomal preparation of CEL, DOX, DOX/CEL and targeted liposome for $24 \mathrm{~h}$. As shown in Figure 4, it was found that the liposomal formulations of each drug alone or in combination could significantly inhibit the proliferation in a dose-dependent manner $(\mathrm{P}<0.05)$.

The $\mathrm{IC}_{50}$ values of DOX and CEL on MCF/ADR cells were evaluated, respectively. As shown in Table S1, the $\mathrm{IC}_{50}$ of DOX and CEL as a single drug-loaded liposome showed the highest concentration to kill $50 \%$ of MCF/ ADR cells, while the co-delivery and peptide modified targeting liposomes only reached approximately quarter of the concentration needed from each drug alone. Besides, the targeting liposomes group showed a significant decrease in the minimum inhibitory concentrations in comparison with other groups. This indicated that the cytotoxicity effect of the co-delivery of DOX and CEL through peptide modified liposomes had remarkable treatment efficacy on killing MCF/ADR cells.

\section{Cellular Uptake}

Firstly, we used flow cytometry to study the cellular uptake efficiency of the four designed DOX formulations: DOX solu, DOX lipo, DOX/CEL lipo, and targeting lipo. Figure 5 reveals obviously that the targeted lipo showed greater cellular entry ability in comparison to other tested formulations, as proved by its strongest intensity. The mean fluorescence intensity for targeting liposome was about 1.41, 2.74, and 5.72-fold stronger than that for DOX/CEL lipo, DOX lipo, and DOX solu respectively after $4 \mathrm{~h}$ incubation, showing a highly significant difference $(\mathrm{P}<0.001)$. The observation of the higher fluorescence signal for targeted liposome is due to the unique peptide structure composed from MTS (mitochondrial targeting signal), polyarginine $\left(\mathrm{R}_{8}\right)$, and three histidine $\left(\mathrm{H}_{3}\right)$. It was reported that the presence of octaarginine had a remarkable capability to assist in cellular internalization. ${ }^{39,40}$

Assumed that flow cytometry only refers to the overall fluorescence intensity, we did confocal imaging to investigate further the intracellular distribution of the liposomes. As shown in Figure S3, DOX was mainly concentrated in the cytoplasm after incubation for $1 \mathrm{~h}$, but more drugs were entered into the nucleus in DOXloaded liposome groups. For all groups, the fluorescence intensity of DOX increased after co-incubated for $2 \mathrm{~h}$ and $4 \mathrm{~h}$. It was worth observing that the DOX of liposome groups remained in the cytoplasm after co-incubation for 4 $\mathrm{h}$, which indicated that the drugs were released in a controlled manner from the liposomes. And it was not difficult to see that cells incubated with targeted liposomes 
A

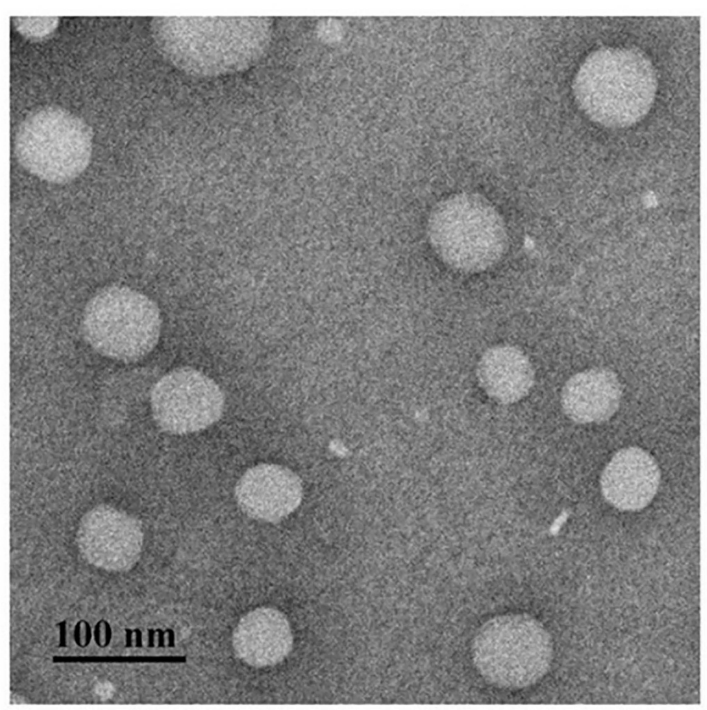

C
B

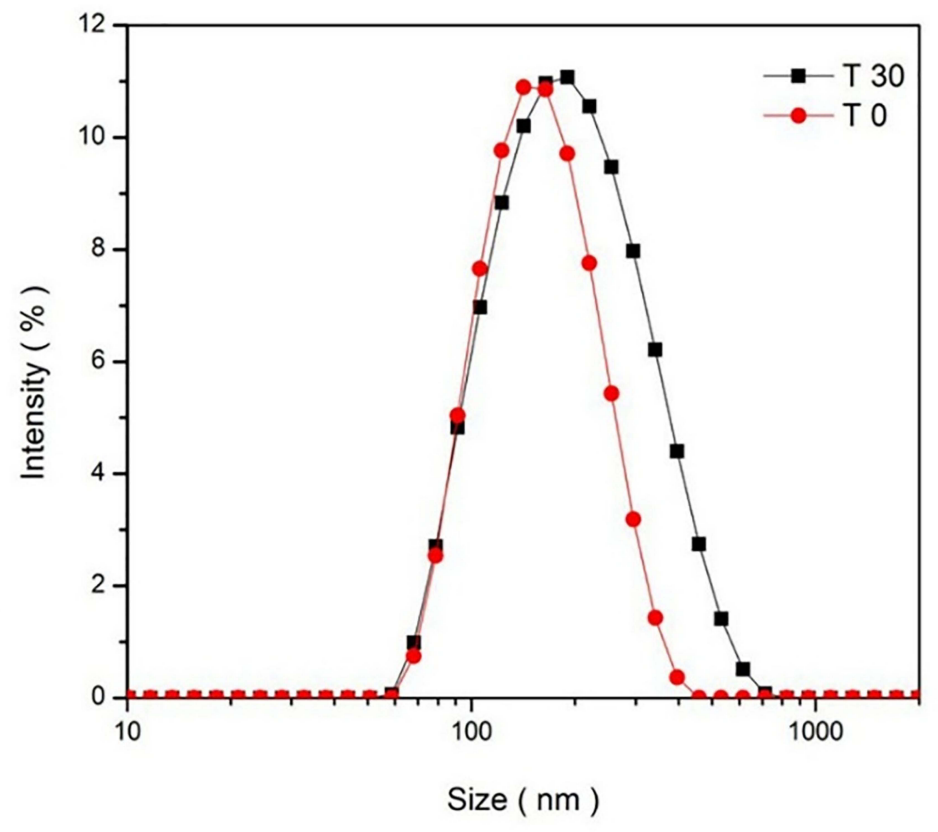

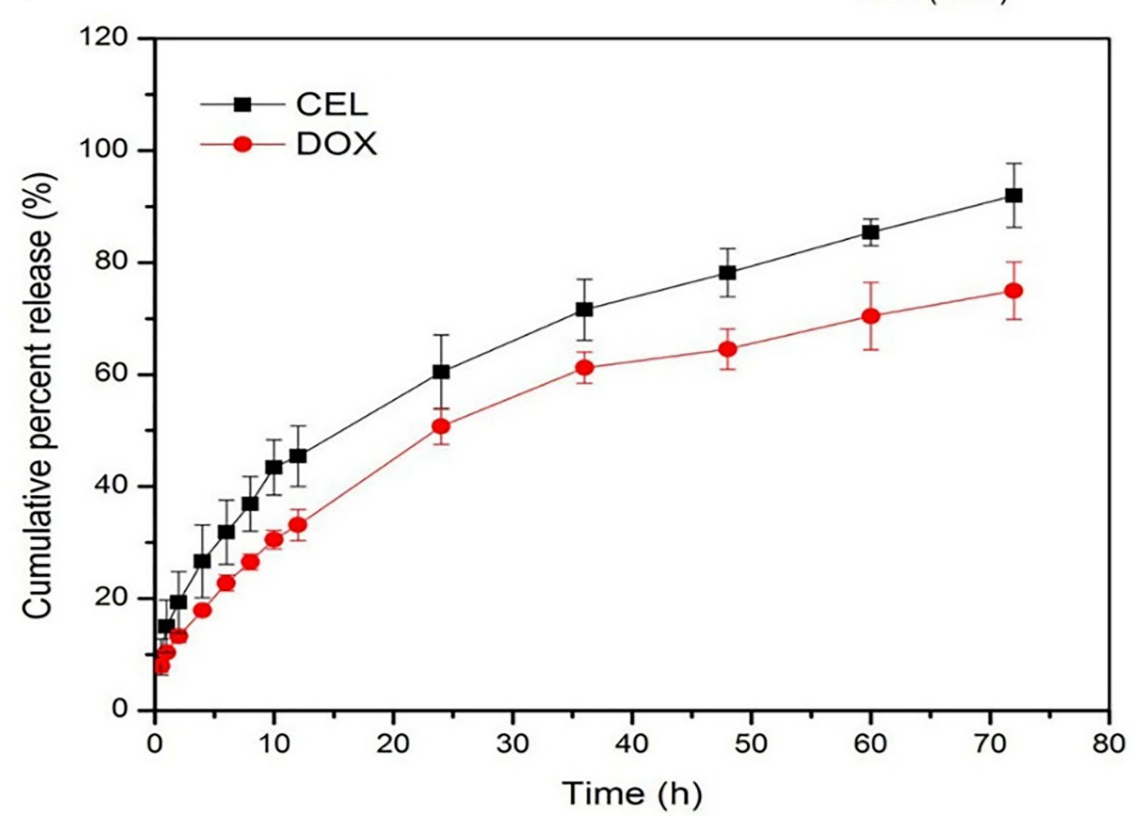

Figure 3 (A) Transmission electron micrographs of targeted liposome. (B) Size distribution of targeted liposome at preparation time (T0) and after one month of storage at $4{ }^{\circ} \mathrm{C}(\mathrm{T} 2)$, and (C) In vitro drug release profiles in phosphate buffer over $72 \mathrm{~h}$ at $37^{\circ} \mathrm{C}$. (C) The release profile of DOX and CEL from the liposome suspension. The results are represented as means \pm SD.

showed intense red fluorescence in the cytosol, suggesting that it had superior intracellular access and more drugs were entered into the nucleus with time. With the data obtained from flow cytometry and fluorescence microscopy, it possibly concluded that the presence of MTS- $\mathrm{R}_{8} \mathrm{H}_{3}$ peptide on the liposome surface enhanced the cell-specific recognition ability and achieved effective cellular internalization.

\section{Subcellular Localization}

The subcellular localization of different formulations in MCF/ADR cells was assessed by CLSM at different times in order to prove if the peptide modified 
Table 2 Stability Study and Characteristics of Loaded Liposomes After I Months of Storage at $4{ }^{\circ} \mathrm{C}$. Values are Means \pm Standard Deviation for Three Independent Experiments

\begin{tabular}{|l|c|c|c|c|c|}
\hline \multirow{2}{*}{ Drug Formulations } & \multicolumn{2}{|c|}{ Encapsulation Efficiency \% } & \multirow{2}{*}{ Particle Size (nm) } & \multirow{2}{*}{ PDI } & \multirow{2}{*}{ Zeta Potential } \\
\cline { 2 - 3 } & Doxorubicin & Celecoxib & & & \\
\hline DOX lipo & $98.35 \% \pm 0.076$ & & $104.03 \pm 1.4$ & $0.124 \pm 1.4$ & $-1.7 \pm 0.2$ \\
DOX/CEL lipo & $96.62 \% \pm 0.0516$ & $97.1 \% \pm 0.0834$ & $151.93 \pm 2.18$ & $0.28 \pm 0.02$ & $-2.46 \pm 0.11$ \\
Targeting lipo & $95.73 \% \pm 0.64$ & $95.4 \% \pm 0.321$ & $191.13 \pm 3.9$ & $0.35 \pm 0.004$ & $-4.57 \pm 0.134$ \\
\hline
\end{tabular}

liposomes were still capable of escaping the lysosomes and targeting the mitochondria. As shown in Figure 6, after the cells treated with DOX solution and DOX
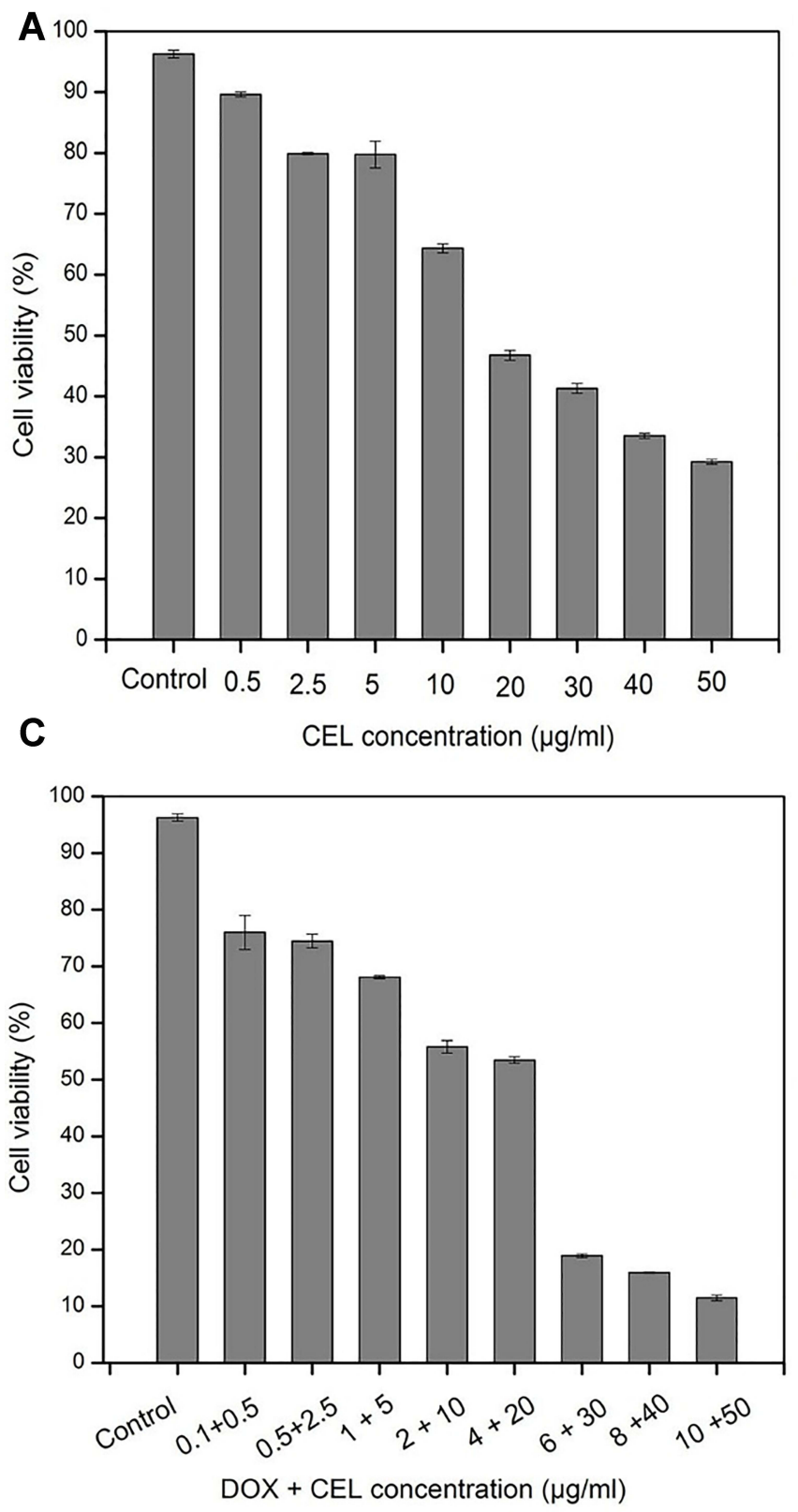

liposomes, the red fluorescence was increased in the cytoplasm following $2 \mathrm{~h}$ incubation. After a prolonged incubation of $4 \mathrm{~h}$, it was observed that strong yellow
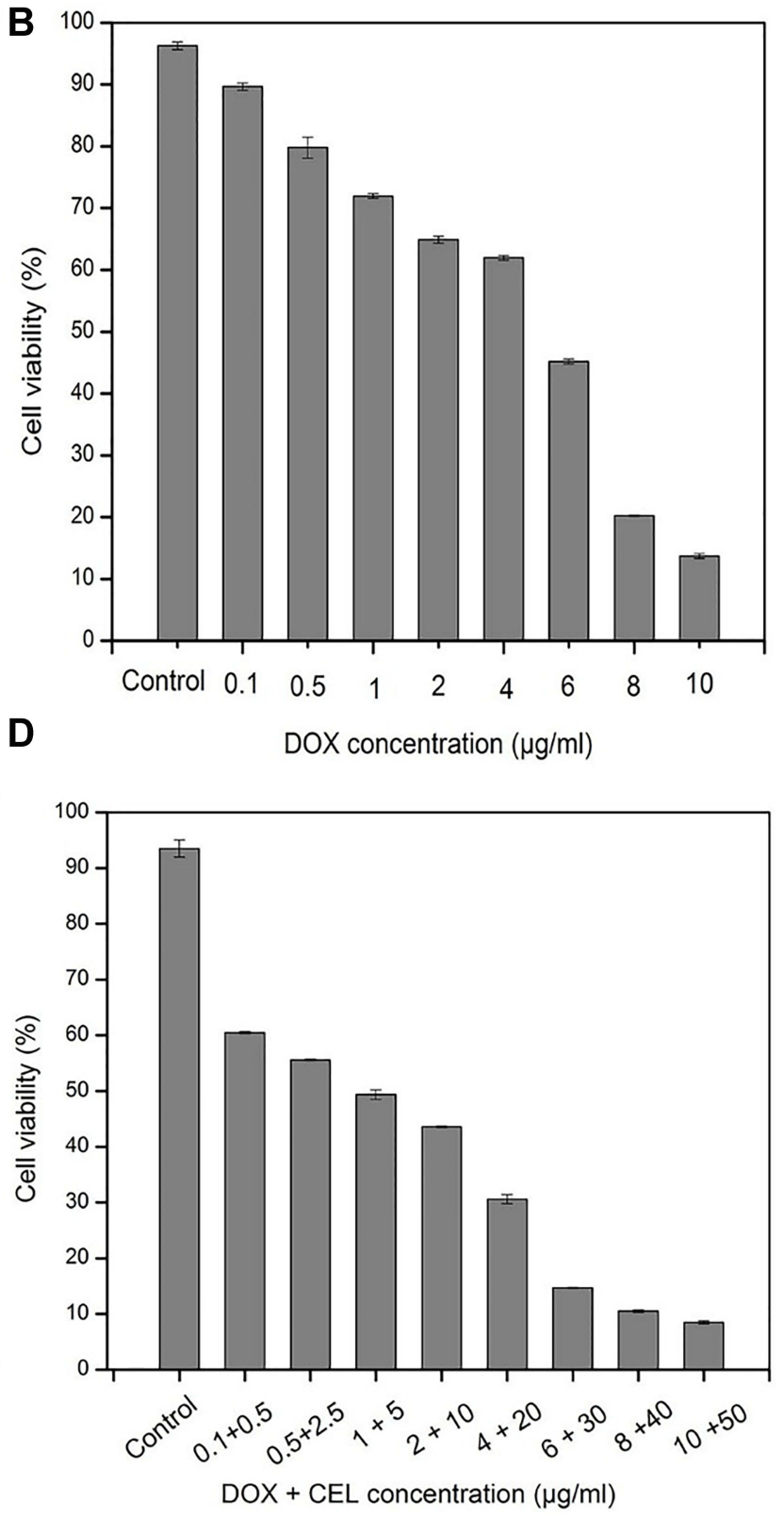

Figure 4 Cytotoxicity against MCF/ADR human breast cancer cells treated with CEL lipo (A), DOX lipo (B), DOX/CEL lipo (C) and targeting lipo (D). Data are reported as the mean \pm standard deviation $(n=3)$. 


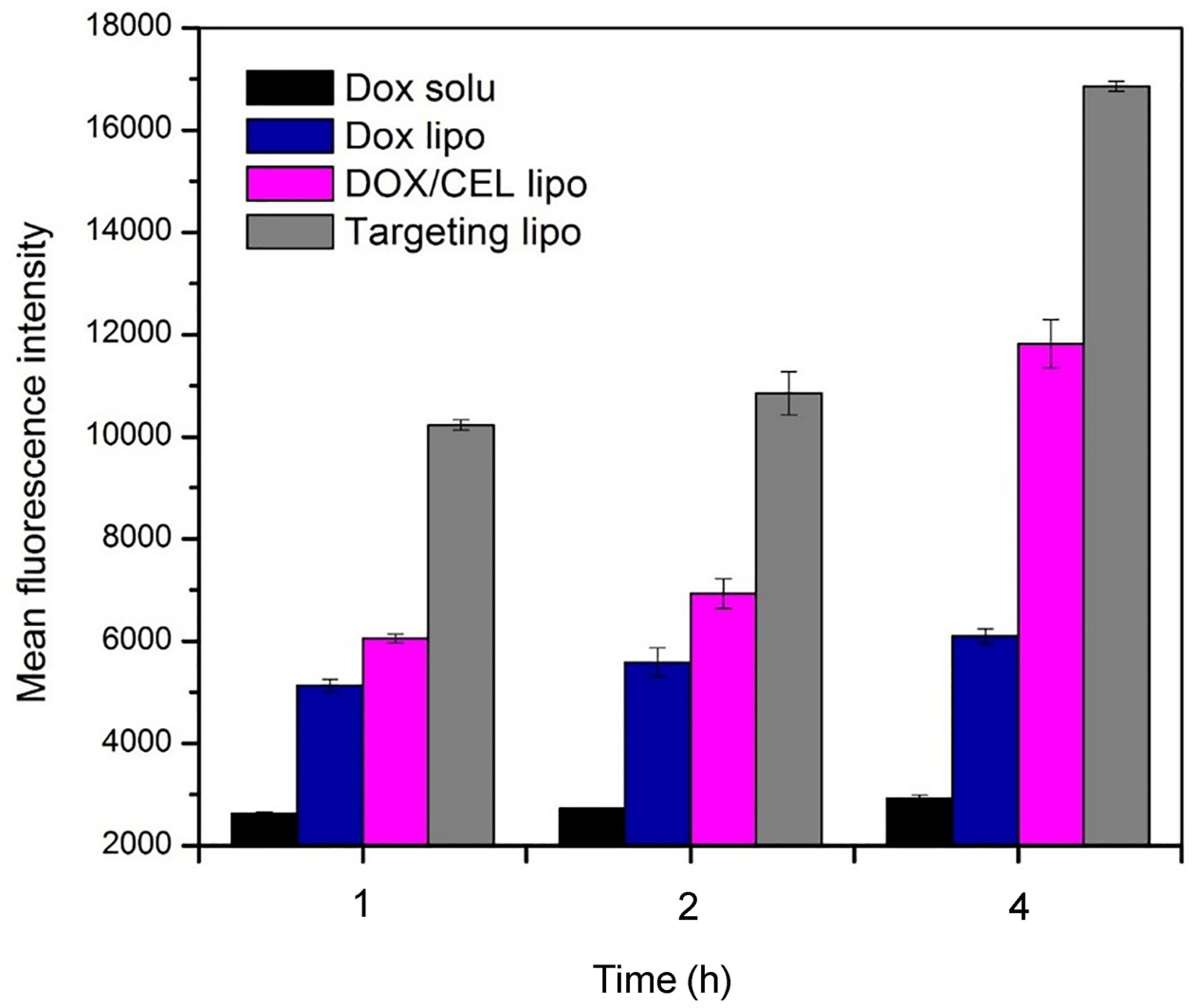

Figure 5 Time-dependent cell uptake of different DOX formulations in MCF/ADR human breast cancer cells. Data are reported as the mean \pm standard deviation $(\mathrm{n}=3$ ).

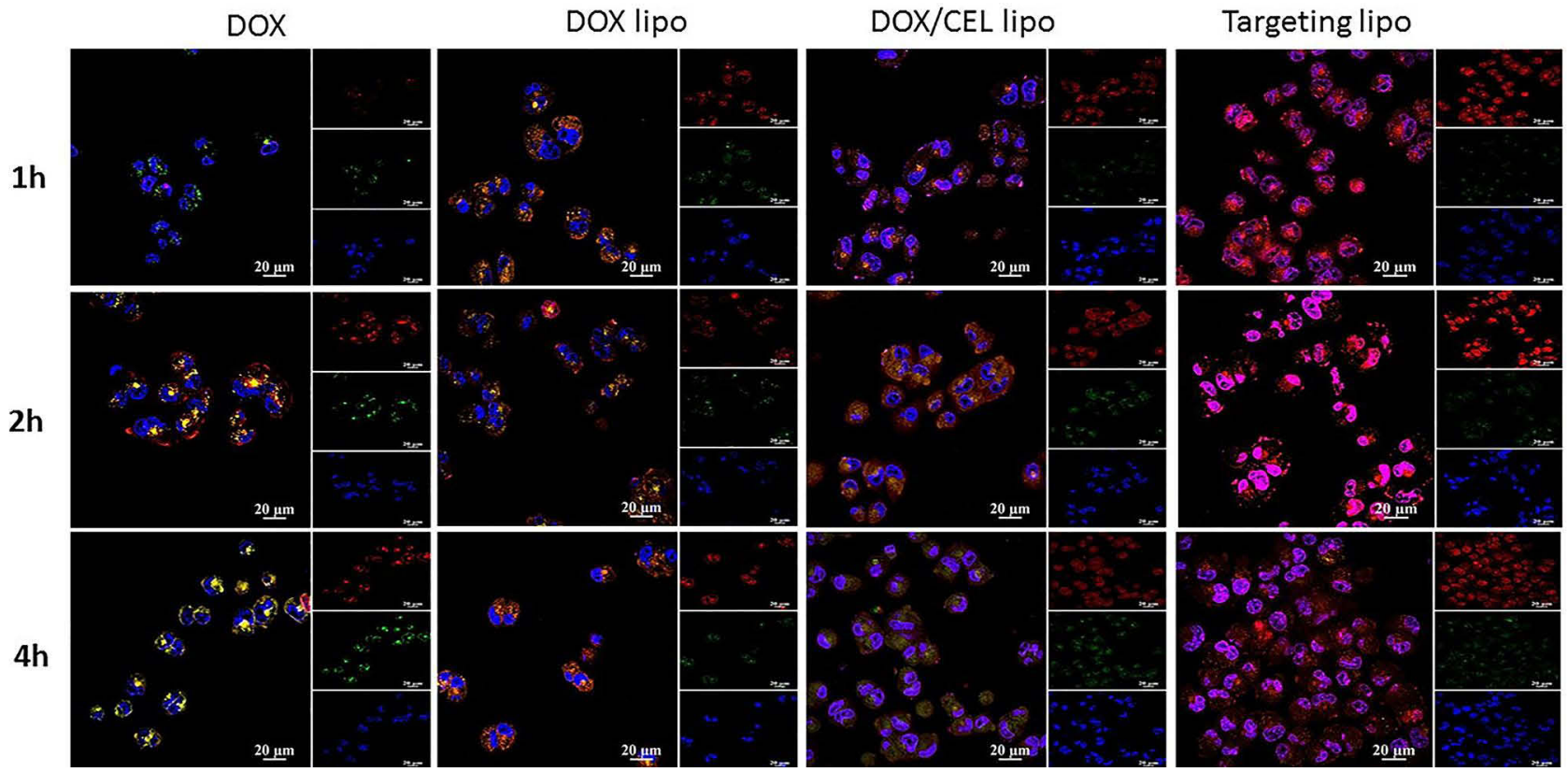

Figure 6 CLSM images of MCF/ADR human breast cancer cells after incubation at different times with DOX, DOX lipo, DOX/CEL lipo, and targeting lipo. DOX was visualized as the red fluorescence, nucleuses labeled with DAPI were shown as the blue fluorescence and green fluorescence indicates lysotracker green labeledmitochondria. Scale bars correspond to $20 \mu \mathrm{m}$ in all images. 


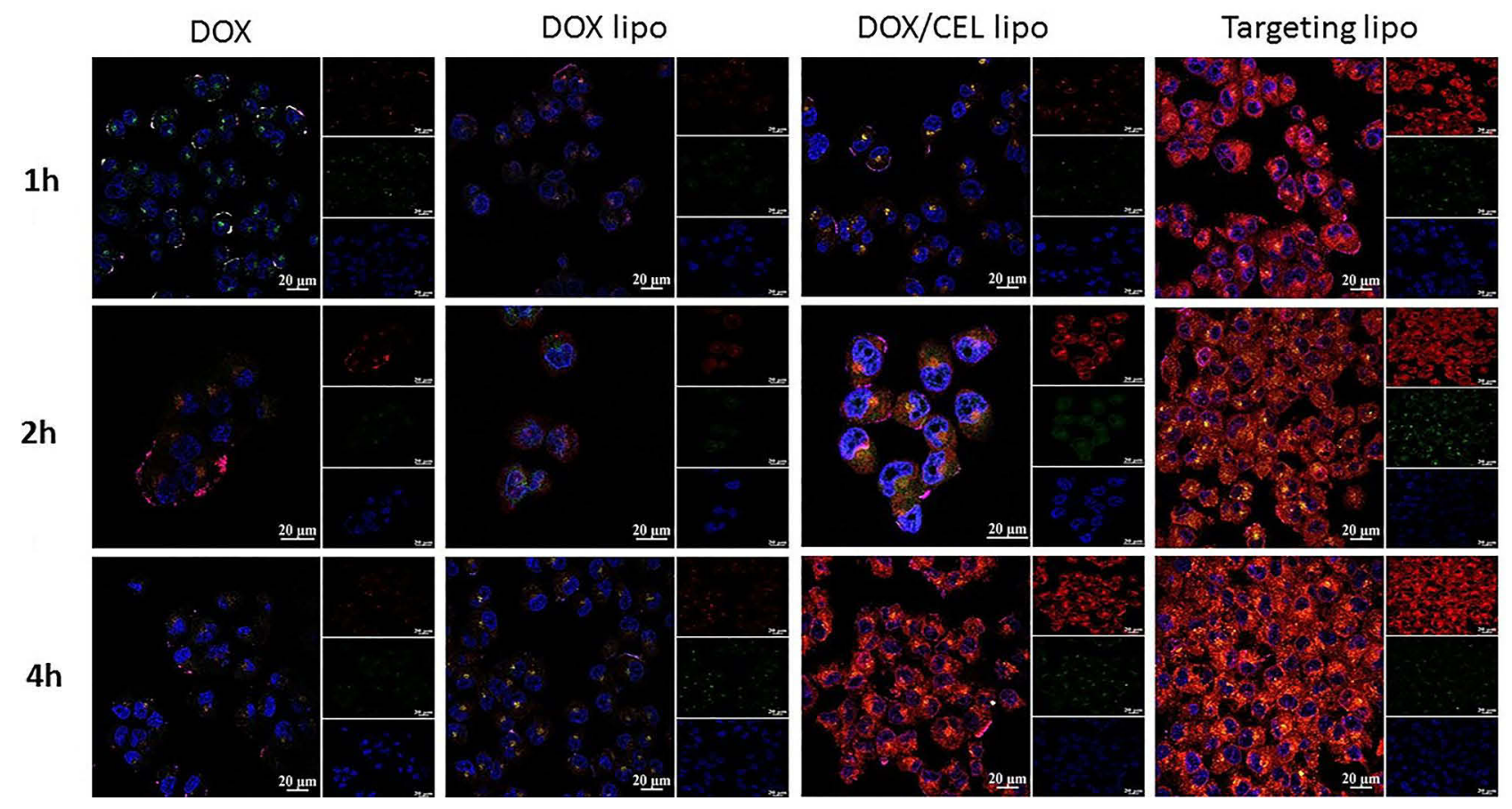

Figure 7 Mitochondrial targeting ability of different DOX formulations in MCF-ADR cells at different times. DOX was visualized as the red fluorescence, nucleuses labeled with DAPI were shown as the blue fluorescence and green fluorescence indicates Mitotracker Green labeled-mitochondria. Scale bars correspond to $20 \mu \mathrm{m}$ in all images.

fluorescence was clearly appeared (overlap of green and red fluorescence in the lysosomes) as a result of DOX trapping in endo-lysosomes. On the other hand, after incubation with DOX/CEL lipo and targeting lipo, the yellow fluorescence was gradually disappeared and the purple fluorescence (overlap of red and blue fluorescence) became more intense after one-hour incubation especially in case of peptide-modified liposomes. This phenomenon was probably attributed to the presence of the histidine-rich molecule used for modification of the liposomes. It was protonation of the imidazole ring of the histidine amino acid to produce a buffering effect, resulting in increasing of the osmotic pressure and disruption of the endosomal membrane and subsequently distribution of targeting liposomes to the mitochondria and nucleus. ${ }^{41,42}$

$\mathrm{MCF} / \mathrm{ADR}$ cells were incubated with different DOX liposomal formulations to track the mitochondrial targeting ability of the liposomes. As shown in Figure 7, the red fluorescence was mostly dispersed in the cytoplasm or localized around the nucleus. As the incubation time increases, the red fluorescence around the nucleus became strengthened. After $4 \mathrm{~h}$ of co-incubation, in case of DOX solu and DOX lipo still did not generate yellow fluorescence or purple fluorescence in the overlay chart (the yellow fluorescence generated from the overlap of the red fluorescence (DOX) with the green fluorescence (Mitotracker)), indicating that DOX mainly accumulate in the lysosomes but does not transport to mitochondria and nucleus. After $2 \mathrm{~h}$ of co-incubation with DOX/CEL lipo, the red fluorescence increased, but the yellow fluorescence still weak, suggesting that part of the DOX/CEL lipo could be transported from the cytoplasm to the nucleus. On the other hand, the yellow fluorescence became shiny enough to be clearly seen after incubation of the cancer cells with the targeting liposome for $1 \mathrm{~h}$ and extremely increased over time. And this back to the presence of MTS molecule in the designed peptide as a mitochondrial targeting entity which is a well-studied natural sequence from the mitochondrial oriented protein aldehyde dehydrogenase (ALDH), ${ }^{43,44}$ which enables the liposome to migrate directly to the mitochondria and consequently increasing the yellow color intensity. That is why DOX/CEL-MTS- ${ }_{8} \mathrm{H}_{3}$ modified liposomes display the greatest cytotoxicity among all tested formulations.

\section{Drug-Induced Changes in Mitochondrial Transmembrane Potential}

Mitochondrial changes, including disruptions in the mitochondrial membrane potential (MMP), are the vital events during the formulations-induced apoptosis. Apoptosis is 

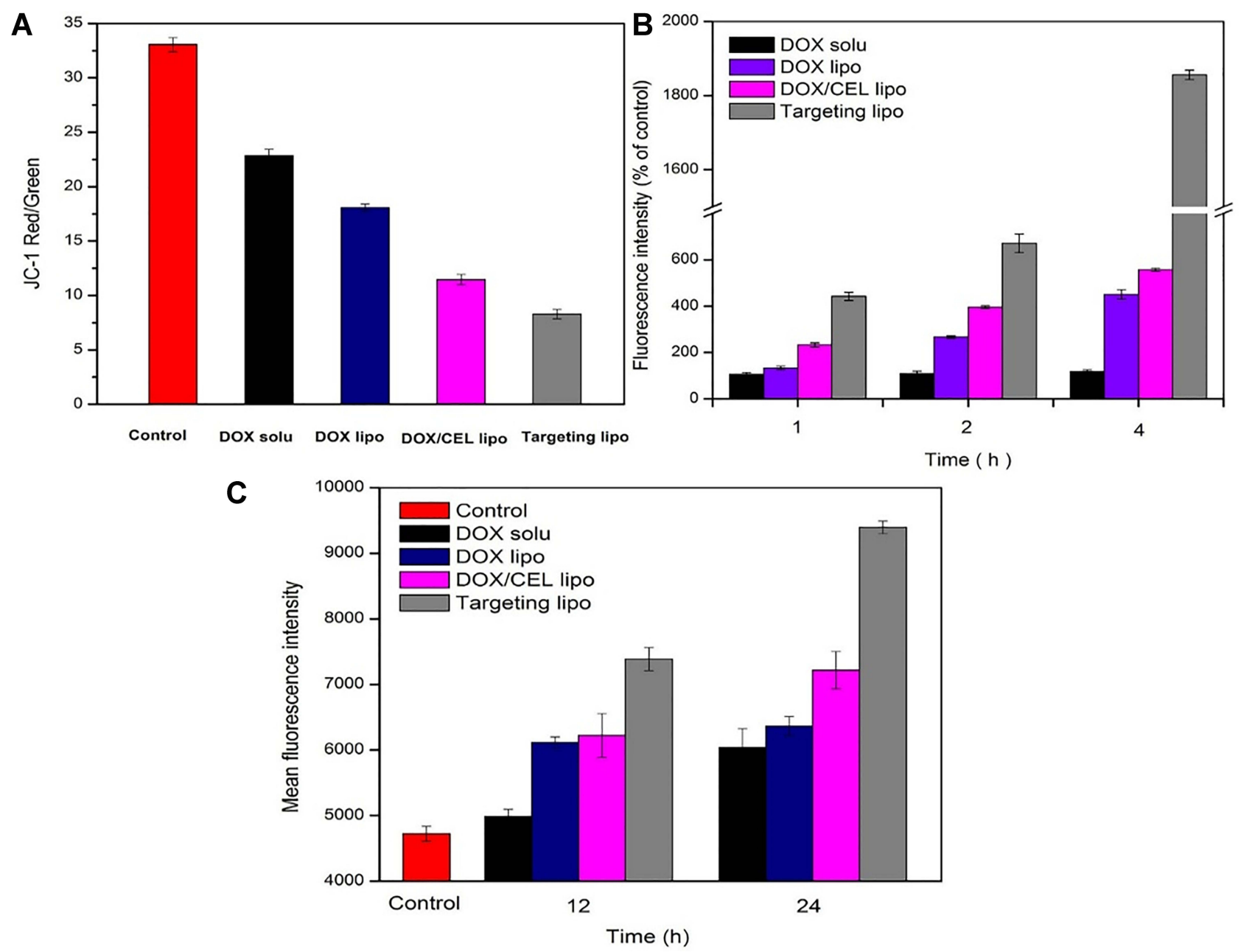

Figure 8 (A) Mitochondrial membrane potential expressed as JC-I aggregate to monomer ratio in MCF/ADR cells incubated for $4 \mathrm{~h}$ at $37^{\circ} \mathrm{C}$. (B) ROS production by different dox formulations. (C) The intracellular accumulation of rhodamine 123 in MCF/ADR cells. The cells were incubated with $5 \mu \mathrm{g} / \mathrm{mL}$ Rh 123 for 30 min, and the intracellular fluorescence was measured to assess the pump function of P-gp. Data are reported as the mean \pm standard deviation ( $n=3$ ) (doxorubicin (DOX), celecoxib (CEL), solution (solu), liposome (lipo)).

Abbreviation: ROS, reactive oxygen species.

commonly associated with mitochondrial membrane depolarization. JC-1 dye has been approved to be more specific for the $\Delta \psi$ than other fluorescent dyes such as rhodamine 123 or DiOC6(3). ${ }^{45,46}$ Mitochondria with normal MMP concentrate JC-1 into aggregates (red fluorescence), while JC-1 forms monomers (green fluorescence) in the depolarized state. ${ }^{47}$ Different DOX formulations were incubated with $\mathrm{MCF} / \mathrm{ADR}$ cells for $4 \mathrm{~h}$ at $37{ }^{\circ} \mathrm{C}$. As shown in Figure 8A, the different liposomes were ranked according to the red/green ratios as follow: DOX solu $>$ DOX lipo > DOX/CEL lipo $>$ and targeting lipo. This indicated that the peptide modified targeting liposomes could be internalized into the tumor cells for targeting the mitochondria, releasing the included DOX and CEL cargoes, resulting in significant depolarization of the MMP.

\section{Determination of the ROS}

Reactive oxygen species production was induced by treatment with different liposomes (Figure 8B). MCF/ADR cells treated with DOX/CEL co-loaded targeted liposomes displayed the highest ROS production ability (18.56 fold more than the control group), which was caused by the mitochondrial targeting sequence that enabled DOX liposome accumulation in the mitochondria. CEL at low concentrations in combination with DOX can abruptly induce 
excessive production of superoxide through disrupting the cellular respiration and decreasing the mitochondrial membrane potential thereby inducing ROS production directly from the mitochondria, consequently, down-regulation of the multidrug resistance (MDR) transporter P-gp occurring and enhancing the sensitivity of MCF/ADR cancer cells to DOX. $^{48}$

\section{Evaluation of P-gP Efflux Assay}

Intracellular accumulation of rhodamine 123 (Rh123) was applied to evaluate the function of membrane P-gp. After cells treatment with different DOX formulations, DOX solu, DOX lipo, DOC/CEL lipo, and Targeting lipo, cells were incubated with $\mathrm{Rh} 123$ for $30 \mathrm{~min}$. The fluorescence intensity of Rh 123 was measured by FCM. As shown in Figure $8 \mathrm{C}$. The data indicated that the mean $\mathrm{Rh} 123$ fluorescence intensity value rank was: Targeting lipo $>$ DOX/CEL lipo $>$ DOX lipo $>$ DOX solu. The intracellular accumulation of Rh 123 in case of DOX/CEL coloaded liposome was significantly $(\mathrm{p}<0.05)$ higher than that of single drug loaded liposomes in a time-dependent manner. Furthermore, the peptide modified liposomes exert the highest inhibitory effect on rhodamine efflux $(\mathrm{p}<0.001)$ compared with other DOX formulations. These results indicated that our targeting liposomes could effectively induce greater drug payload to be delivered to the target cell and effectively inhibit doxorubicin-induced overexpression and function of $\mathrm{P}$-gp in MCF/ADR cells. Previously published literature reported that the overexpression of the multicellular prostate tumor spheroids for $\mathrm{P}$-gp-mediated MDR is revoked under elevated intracellular ROS level conditions. ${ }^{49}$ And these data consistent with the previous findings that celecoxib can rapidly enhance the mitochondrial superoxide production from cancer cells within minutes leading to extensive ROS-dependent apoptosis in murine melanoma B16F10 cells. ${ }^{50}$ But a deeper understanding of this accumulation mechanism is urgently needed and could lead to significantly more effective drug delivery in anticancer therapy.

\section{Conclusions}

In this research, efficient DOX/CEL-targeting liposomes were successfully prepared as a novel drug delivery carrier due to the targeting ability and therapeutic efficiency to breast cancer cells. Liposomes displayed a nanometric size of approximately 100-150 $\mathrm{nm}$ in diameter and spherically shaped vesicles with high encapsulation efficiency and showed prominent storage stability for one month. DOX/ CEL targeted liposomes achieved a significant reduction in cell viability in comparison with the other drug-loaded liposomes. MTS- $\mathrm{R}_{8} \mathrm{H}_{3}$ modified DOX/CEL liposome significantly increased the in vitro intracellular retention and accumulation of doxorubicin and achieved the best lysosomal escape and mitochondrial targeting ability with the highest ROS production efficiency and significant inhibition of P-gp efflux activity in MCF/ADR cells. These results indicated that $\mathrm{MTS}-\mathrm{R}_{8} \mathrm{H}_{3}$ modified DOX/CEL liposomes can be used as a promising drug delivery system for preventing of chemoresistance of human breast cancer cell line and should be considered for future trials.

\section{Data Sharing Statement}

All data associated with this study are present in the paper and the Supplementary Materials.

\section{Acknowledgements}

This work was supported by the Natural Science Foundation of Jiangsu Province (BK20201344), China Postdoctoral Science Foundation (2019M660166), National Natural Science Foundation of China (81703437 and 81872220), Postdoctoral Innovation Project of Shandong Province (202002039), Basic Public Welfare Research Project of Zhejiang Province (LGF20H300012) and the Science and Technology Bureau of Jiaxing (2019AY32009).

\section{Disclosure}

The authors declare that they have no conflicts of interest for this work.

\section{References}

1. Siegel RL, Miller KD, Jemal A. Cancer statistics, 2020. CA Cancer J Clin. 2020;70(1):7-30. doi:10.3322/caac.21590

2. Mielczarek L, Krug P, Mazur M, et al. In the triple-negative breast cancer MDA-MB-231 cell line, sulforaphane enhances the intracellular accumulation and anticancer action of doxorubicin encapsulated in liposomes. Int $J$ Pharm. 2019;558:311-318. doi:10.1016/j. ijpharm.2019.01.008

3. Zou LL, Ding WP, Zhang YY, et al. Peptide-modified vemurafenib-loaded liposomes for targeted inhibition of melanoma via the skin. Biomaterials. 2018;182:1-12. doi:10.1016/j.biomaterial s.2018.08.013

4. Tang J, Wang Q, Yu Q, et al. A stabilized retro-inverso peptide ligand of transferrin receptor for enhanced liposome-based hepatocellular carcinoma-targeted drug delivery. Acta Biomater. 2019;83:379-389. doi:10.1016/j.actbio.2018.11.002

5. Xu HB, Shen FM, Lv QZ. Celecoxib enhanced the cytotoxic effect of cisplatin in chemo-resistant gastric cancer xenograft mouse models 
through a cyclooxygenase-2-dependent manner. Eur J Pharmacol. 2016;776:1-8. doi:10.1016/j.ejphar.2016.02.035

6. Tian JY, Guo FG, Chen YY, et al. Nanoliposomal formulation encapsulating celecoxib and genistein inhibiting COX-2 pathway and Glut-1 receptors to prevent prostate cancer cell proliferation. Cancer Lett. 2019;448:1-10. doi:10.1016/j.canlet.2019.01.002

7. Kim H, Yim G, Kim Y. Celecoxib and paclitaxel synergistically induce apoptosis in the human ovarian cancer cell line OVCAR-3. Gynecol Oncol. 2013;130(1):126-132. doi:10.1016/j.ygyno.2013.04.362

8. Meng XY, Zhang Q, Zheng GB, et al. Doxorubicin combined with celecoxib inhibits tumor growth of medullary thyroid carcinoma in xenografted mice. Oncol Lett. 2014;7(6):2053-2058. doi:10.3892/ ol.2014.2050

9. Chen $\mathrm{C}, \mathrm{Xu} \mathrm{W}$, Wang CM. Combination of celecoxib and doxorubicin increases growth inhibition and apoptosis in acute myeloid leukemia cells. Leuk Lymphoma. 2013;54(11):2517-2522. doi:10.3109/ 10428194.2013.781170

10. Kozlu S, Sahin A, Ultav G, et al. Development and in vitro evaluation of doxorubicin and celecoxib co-loaded bone targeted nanoparticles. J Drug Deliv Sci Technol. 2018;45:213-219. doi:10.1016/j.jddst.2018.02.004

11. Fantappiè O, Solazzo M, Lasagna N, Platini F, Tessitore L, Mazzanti R. P-glycoprotein mediates celecoxib-induced apoptosis in multiple drug-resistant cell lines. Cancer Res. 2007;67 (10):4915-4923.

12. Huang L, Wang C, Zheng W, et al. Effects of celecoxib on the reversal of multidrug resistance in human gastric carcinoma by downregulation of the expression and activity of P-glycoprotein. Anticancer Drugs. 2007;18(9):1075-1080. doi:10.1097/CAD.0b013e3281c49d7a

13. Sung MW, Lee DY, Park SW, et al. Celecoxib enhances the inhibitory effect of 5-FU on human squamous cell carcinoma proliferation by ROS production. Laryngoscope. 2016;127(4):E117-E123.

14. Soukupová K, Rudolf E. Suppression of proliferation and activation of cell death by sodium selenite involves mitochondria and lysosomes in chemoresistant bladder cancer cells. J Trace Elem Med Biol. 2019;52:58-67. doi:10.1016/j.jtemb.2018.11.009

15. Guo Z, Sevrioukova IF, Denisov IG, et al. Heme binding biguanides target cytochrome P450-dependent cancer cell mitochondria. Cell Chem Biol. 2017;24(10):1259-1275.e6. doi:10.1016/j.chembiol.20 17.08 .009

16. Li SY, Cheng H, Xie BR, et al. Mitochondria targeted cancer therapy using ethidium derivatives. Mater Today Chem. 2017;6:34-44. doi:10.1016/j.mtchem.2017.09.002

17. Zhao YJ, Sun LM, Wang RR, et al. The effects of mitochondria-associated long noncodings RNAs in cancer mitochondria: new players in an old arena. Crit Rev Oncol Hematol. 2018;131:76-82. doi:10.1016/j.critrevonc.2018.08.005

18. Copolovici DM, Langel K, Eriste E, et al. Cell-penetrating peptides: design, synthesis, and applications. ACS Nano. 2014;8(3):1972-1994. doi:10.1021/nn4057269

19. Walrant A, Cardon S, Burlina F, et al. Membrane crossing and membranotropic activity of cell-penetrating peptides: dangerous liaisons? Acc Chem Res. 2017;50(12):2968-2975. doi:10.1021/acs. accounts. $7 \mathrm{~b} 00455$

20. Freire JM, Veiga AS, Inês R, et al. Nucleic acid delivery by cell penetrating peptides derived from dengue virus capsid protein: design and mechanism of action. Febs J. 2014;281(1):191-215. doi:10.1111/ febs. 12587

21. Ahmed KS, Shan XT, Mao J, et al. Derma roller ${ }^{\circledR}$ microneedlesmediated transdermal delivery of doxorubicin and celecoxib coloaded liposomes for enhancing the anticancer effect. Mater Sci Eng C Mater Biol Appl. 2019;99:1448-1458. doi:10.1016/j. msec.2019.02.095

22. Yu J, Li W, Yu D. Atrial natriuretic peptide modified oleate adenosine prodrug lipid nanocarriers for the treatment of myocardial infarction: in vitro and in vivo evaluation. Drug Des Devel Ther. 2018;12:1697-1706. doi:10.2147/DDDT.S166749

23. Iden DL, Allen TM. In vitro and in vivo comparison of immunoliposomes made by conventional coupling techniques with those made by a new post-insertion approach. Biochim Biophys Acta Biomembr. 2001;1513(2):207-216. doi:10.1016/S0005-2736(01)00357-1

24. Song SX, Liu D, Peng JJ, et al. Peptide ligand-mediated liposome distribution and targeting to EGFR expressing tumor in vivo. Int $J$ Pharm. 2008;363(1):155-161. doi:10.1016/j.ijpharm.20 08.07.012

25. Li CL, Cui JX, Wang CX, et al. Development of pegylated liposomal vinorelbine formulation using "post-insertion" technology. Int $J$ Pharm. 2010;391(1):230-236. doi:10.1016/j.ijpharm.20 10.03.004

26. Silverman L, Barenholz Y. In vitro experiments showing enhanced release of doxorubicin from doxil ${ }^{\mathbb{B}}$ in the presence of ammonia may explain drug release at tumor site. Nanomedicine. 2015;11 (7):1841-1850. doi:10.1016/j.nano.2015.06.007

27. Fetih G, Fathalla D, El-Badry M. Liposomal gels for site-specific, sustained delivery of celecoxib: in vitro and in vivo evaluation. Drug Dev Res. 2014;75(4):257-266. doi:10.1002/ddr.21179

28. Scaduto RC, Grotyohann LW. Measurement of mitochondrial membrane potential using fluorescent rhodamine derivatives. Biophys $J$. 1999;76(1):469-477. doi:10.1016/S0006-3495(99)77214-0

29. Szwed M, Laroche-Clary A, Robert J, et al. Efficacy of doxorubicin-transferrin conjugate in apoptosis induction in human leukemia cells through reactive oxygen species generation. Cell Oncol. 2016;39(2):107-118. doi:10.1007/s13402-015-0256-2

30. Yin J, Guo JB, Zhang Q, et al. Doxorubicin-induced mitophagy and mitochondrial damage is associated with dysregulation of the PINK1/ parkin pathway. Toxicol in Vitro. 2018;51:1-10. doi:10.1016/j. tiv.2018.05.001

31. Wang JS, Ho FM, Kang HC, et al. Celecoxib induces heme oxygenase-1 expression in macrophages and vascular smooth muscle cells via ROS-dependent signaling pathway. Naunyn Schmiedebergs Arch Pharmacol. 2011;383(2):159-168. doi:10.1007/s00210-0100586-6

32. Ma M, Yang X, Zhao L, et al. Celecoxib enhances sensitivity to chemotherapy drugs of T-cell lymphoma. Oncol Lett. 2018;15 (4):4649-4656.

33. Lisa S, Tejaswi V, Fatemeh M, et al. Advances and challenges of liposome assisted drug delivery. Front Pharmacol. 2015;6 (127):27-31.

34. Kalyane D, Raval N, Maheshwari R, et al. Employment of enhanced permeability and retention effect (EPR): nanoparticle-based precision tools for targeting of therapeutic and diagnostic agent in cancer. Mater Sci Eng C Mater Biol Appl. 2019;98:1252-1276. doi:10.1016/j.msec.2019.01.066

35. Sabeti B, Noordin MI, Mohd S, et al. Development and characterization of liposomal doxorubicin hydrochloride with palm oil. Biomed Res Int. 2014;2014:765426. doi:10.1155/2014/765426

36. Silverman L, Barenholz Y. In vitro experiments showing enhanced release of doxorubicin from doxil in the presence of ammonia may explain drug release at tumor site. Nanomedicine. 2015;11(7):31-52.

37. Ahmed KS, Hussein SA, Ali AH, et al. Liposome: composition, characterisation, preparation, and recent innovation in clinical applications. J Drug Target. 2018;27:1-58.

38. Farzaneh H, Ebrahimi NM, Mashreghi M, et al. A study on the role of cholesterol and phosphatidylcholine in various features of liposomal doxorubicin: from liposomal preparation to therapy. Int $J \quad$ Pharm. 2018;551(1):300-308. doi:10.1016/j. ijpharm.2018.09.047

39. Khalil IA, Kogure K, Futaki S, et al. Octaarginine-modified liposomes: enhanced cellular uptake and controlled intracellular 
trafficking. Int $J$ Pharm. 2008;354(1):39-48. doi:10.1016/j. ijpharm.2007.12.003

40. Kitagishi H, Hata DS, Itakura T, et al. Cellular uptake of octaarginine-conjugated tetraarylporphyrin included by per-O-methylated $\beta$ cyclodextrin. Org Biomol Chem. 2013;11(19):3203-3211. doi: $10.1039 / \mathrm{c} 3 \mathrm{ob} 27248 \mathrm{f}$

41. Varkouhi AK, Scholte M, Storm G, et al. Endosomal escape pathways for delivery of biologicals. J Control Release. 2011;151 (3):220-228. doi:10.1016/j.jconrel.2010.11.004

42. Moreira C, Oliveira H, Pires LR, et al. Improving chitosan-mediated gene transfer by the introduction of intracellular buffering moieties into the chitosan backbone. Acta Biomater. 2009;5(8):2995-3006. doi:10.1016/j.actbio.2009.04.021

43. Wang Y, Weiner H. The presequence of rat liver aldehyde dehydrogenase requires the presence of an alpha-helix at its $\mathrm{N}$-terminal region which is stabilized by the helix at its C termini. J Biol Chem. 1993;268 (7):4759-4765. doi:10.1016/S0021-9258(18)53462-1

44. Lin R, Zhang P, Cheetham AG, et al. Dual peptide conjugation strategy for improved cellular uptake and mitochondria targeting. Bioconjug Chem. 2015;26(1):71-77. doi:10.1021/bc500408p

45. Perry SW, Norman JP, Barbieri J, et al. Mitochondrial membrane potential probes and the proton gradient: a practical usage guide. Biotechniques. 2011;50(2):98-115. doi:10.2144/000113610
46. Anthony M, Hong Y, Kemp BK, et al. Evaluation of fluorescent dyes for the detection of mitochondrial membrane potential changes in cultured cardiomyocytes. Cardiovasc Res. 2000;1:126-138.

47. Qiu L, Qiao MX, Chen Q, et al. Enhanced effect of pH-sensitive mixed copolymer micelles for overcoming multidrug resistance of doxorubicin. Biomaterials. 2014;35(37):9877-9887. doi:10.1016/j. biomaterials.2014.08.008

48. Wartenberg M, Ling FC, Schallenberg M, et al. Down-regulation of intrinsic P-glycoprotein expression in multicellular prostate tumor spheroids by reactive oxygen species. J Biol Chem. 2001;276 (20):17420-17428. doi:10.1074/jbc.M100141200

49. Wartenberg M, Hoffmann E, Schwindt H, et al. Reactive oxygen species-linked regulation of the multidrug resistance transporter p-glycoprotein in Nox-1 overexpressing prostate tumor spheroids. FEBS Lett. 2005;579(20):4541-4549. doi:10.1016/j.febslet.20 05.06.078

50. Pritchard R, Rodríguez-Enríquez S, Pacheco-Velázquez SC, et al. Celecoxib inhibits mitochondrial $\mathrm{O}_{2}$ consumption, promoting ros dependent death of murine and human metastatic cancer cells via the apoptotic signalling pathway. Biochem Pharmacol. 2018;154:318-334. doi:10.1016/j.bcp.2018.05.013

\section{Publish your work in this journal}

Drug Design, Development and Therapy is an international, peerreviewed open-access journal that spans the spectrum of drug design and development through to clinical applications. Clinical outcomes, patient safety, and programs for the development and effective, safe, and sustained use of medicines are a feature of the journal, which has also been accepted for indexing on PubMed Central. The manuscript management system is completely online and includes a very quick and fair peer-review system, which is all easy to use. Visit http://www. dovepress.com/testimonials.php to read real quotes from published authors. 